\title{
Adsorption-Luminescent Determination of Y(III) Using 8-oxyquinoline Derivatives Fixed on the Silica Surface
}

\author{
Olga V. Buyko*, Vladimir N. Losev \\ and Alexander F. Shimanskii \\ Research Engineering Centre 'Kristall' \\ of Siberian Federal University \\ Krasnoiarsk, Russian Federation
}

\begin{abstract}
Silicas, sequentially modified with polyhexamethylene guanidine and 8-hydroxyquinoline-5sulfonic acid ( $\mathrm{SiO}_{2}$-PHMG-oxine) or 7-iodine-8-hydroxyquinoline-5-sulfonic acid ( $\mathrm{SiO}_{2}$-PHMG-ferron), have been proposed for the adsorption-luminescent determination of Y(III) in natural waters. Complex compounds of Y(III) are formed on the surface of adsorbents during adsorption from solutions at $\mathrm{pH}$ $6-7$, which luminesce in a yellow-green color ( $\lambda_{\text {lum }}=485 \mathrm{~nm}\left(\mathrm{SiO}_{2}-\mathrm{PHMG}-\right.$ oxine $)$ and $\lambda_{\text {lum }}=490 \mathrm{~nm}$ $\left(\mathrm{SiO}_{2}\right.$-PHMG-ferron)). This is the basis for the method of its sorption-luminescent determination. The detection limit of $\mathrm{Y}(\mathrm{III})$, calculated according to the $3 \mathrm{~s}$ criterion, is $1 \mu \mathrm{g} / \mathrm{L}$ ( $\left.\mathrm{SiO}_{2}-\mathrm{PHMG}-\mathrm{oxine}\right)$ and 2 $\mu \mathrm{g} / \mathrm{L}$ ( $\mathrm{SiO}_{2}-\mathrm{PHMG}-$ ferron), the analytical range is $4-400 \mu \mathrm{g} / \mathrm{L}\left(\mathrm{SiO}_{2}-\mathrm{PHMG}-\mathrm{oxine}\right)$ and $6-500 \mu \mathrm{g} / \mathrm{L}$ $\left(\mathrm{SiO}_{2}\right.$-PHMG-ferron). The developed methods were tested in the determination of yttrium in the Yenisei and Kacha rivers of the Krasnoyarsk Krai.
\end{abstract}

Keywords: adsorption-luminescent determination, yttrium(III), modified silicas, ferron.

(C) Siberian Federal University. All rights reserved

This work is licensed under a Creative Commons Attribution-NonCommercial 4.0 International License (CC BY-NC 4.0).

* Corresponding author E-mail address: obuyko@sfu-kras.ru 


\title{
Сорбционно-люминесцентное определение Ү(III) производными 8-оксихинолина, закрепленными на поверхности кремнезема
}

\author{
О. В. Буйко, В.Н. Лосев, А. Ф. Шиманский \\ Научно-исследовательский инженерный изентр «Кристалл» \\ Сибирского федерального университета \\ Российская Федеращия, Красноярск
}

\begin{abstract}
Аннотация. Кремнеземы, последовательно модифицированные полигексаметиленгуанидином и 8 -оксихинолин-5-сульфокислотой $\left(\mathrm{SiO}_{2}\right.$-ПГМГ-оксин) или 7-йод-8-оксихинолин-5сульфокислотой ( $\mathrm{SiO}_{2}$-ПГМГ-феррон), предложены для сорбционно-люминесцентного определения Y(III) в природных водах. Образование на поверхности сорбентов комплексных соединений, люминесцирующих желто-зеленым цветом $\left(\lambda_{\text {люм }}=485\right.$ нм $\left(\mathrm{SiO}_{2}\right.$-ПГМГ-оксин) и $\lambda_{\text {люм }}=490 \mathrm{нм}$ ( $\mathrm{SiO}_{2}$-ПГМГ-феррон), в процессе сорбции Y(III) из растворов при рН 6-7 положено в основу разработки методики его сорбционно-люминесцентного определения. Предел обнаружения $\mathrm{Y}(\mathrm{III})$, рассчитанный по $3 s$-критерию, составляет 1 мкг/л $\left(\mathrm{SiO}_{2}\right.$-ПГМГ-оксин) и 2 мкг/л $\left(\mathrm{SiO}_{2}\right.$ ПГМГ-феррон), диапазон определяемых содержаний - 4-400 мкг/л ( $\mathrm{SiO}_{2}$-ПГМГ-оксин) и 6-500 мкг/л ( $\mathrm{SiO}_{2}$-ПГМГ-феррон). Разработанные методики опробованы при определении иттрия в реках Енисей и Кача Красноярского края.
\end{abstract}

Ключевые слова: сорбционно-люминесцентное определение, иттрий(III), модифицированные кремнеземы, феррон.

Цитирование: Буйко, О. В. Сорбционно-люминесцентное определение Ү(ІІІ) производными 8-оксихинолина, закрепленными на поверхности кремнезема / О. В. Буйко, В. Н. Лосев, А. Ф. Шиманский // Журн. Сиб. федер. ун-та. Химия, 2021, 14(3). С. 337-349. DOI: 10.17516/1998-2836-0242

\section{Введение}

В последние десятилетия редкоземельные элементы (РЗЭ) стали незаменимы в различных высоких технологиях, таких как сверхпроводники или компоненты для гибридных автомобилей, люминесцентные лампы и светодиодные светильники, ЖК-экраны, лазеры, а также в медицине [1]. Поскольку РЗЭ могут способствовать росту растений и животных, они широко используются и в качестве кормовых добавок и микроэлементных удобрений в сельскохозяйственном производстве [2-3]. Содержание Р3Э в китайских удобрениях колеблется от 25,8 мг/кг (Тb) до 24100 мг/кг (Cе) [4]. Применение РЗЭ в китайском сельскохозяйственном производстве растет год от года, достигая нескольких тысяч тонн в год [5]. Явление стимуляции роста в низких концентрациях и ингибирование в высоких концентрациях известно как «эффект гормезиса» и было зарегистрировано для РЗЭ в тканях растений и животных в исследованиях как in vivo, так и in vitro $[6,7]$. Однако длительное потребление низких доз РЗЭ может привести к аберрации структуры кости и ткани и даже вызвать генерацию генетической токсичности в клетках костного мозга [8], РЗЭ 
могут проникать в центральную нервную систему [9]. У позвоночных, беспозвоночных и растений были задокументированы побочные эффекты, такие как патология органов, цитогенетическое и эмбриологическое повреждение и торможение роста [10].

В результате столь активного использования РЗЭ все больше и больше распространяются в окружающей среде и могут попадать в организм человека через пищевую цепь. Европейское агентство по безопасности и гигиене труда включило РЗЭ в список «Новые и возникающие риски для безопасности и гигиены труда» [11].

Иттрий имеет широкое техническое и биологическое применение: в качестве одного из элементов для получения твердотельных лазеров (иттрий-гадолиниевый гранат), в радиоэлектронике и телевидении, в медицине при лечении соединениями иттрия многих онкологических заболеваний. Среди редкоземельных элементов иттрий обладает высоким токсическим действием на живые организмы, проявляющимся патологическими изменениями в печени и почках [12]. В организм человека поступление иттрия возможно преимущественно с водой в местностях с высоким его содержанием в почвах.

Хотя современные аналитические методы, такие как атомно-эмиссионная спектроскопия и масс-спектрометрия с индуктивно-связанной плазмой (АЭС-ИСП, МС-ИСП), позволяют определять иттрий в природных водах с пределами обнаружения на уровне 0,1-3 нг/л [13], актуальным остается и одноэлементное экспрессное, простое и доступное люминесцентное определение иттрия с достаточной чувствительностью. При этом эффективно сочетание люминесцентного определения с предварительным сорбционным концентрированием и определением непосредственно в фазе сорбента.

Для люминесцентного определения иттрия предложен ряд реагентов, таких как 1-гидроксиантрахинон-2 карбоновая кислота [14], 4,4-метилен-бис-(1,2-дигидро-1,5-диметил-2фенил-3-пиразолон) (диантипирилметан, ДАМ) и 8-гидроксихинолин (оксин) [15-16], а также и их производные. Закрепление производных 8-гидроксихинолина на поверхности твердых носителей позволяет не только проводить люминесцентное определение иттрия, но и концентрировать микрокомпонент на небольшой навеске сорбента и, как следствие, снижать относительные пределы его обнаружения.

В данной работе предложено использовать кремнезем в качестве основы сорбента, поскольку он не имеет собственной окраски и люминесценции. Закрепление сульфопроизводных 8-гидроксихинолина на поверхности кремнезема, предварительно обработанного водным раствором полигексаметиленгуанидина (ПГМГ), происходит за счет образования межмолекулярных связей между реагентами и силанольными группами матрицы. ПГМГ как положительно заряженный полиэлектролит выполняет функцию связующего реагента между функциональными группами (производные 8-гидроксихинолина) и твердой матрицей (кремнезем).

\section{Материалы и методика}

\section{Реактивы}

Исходный раствор 25 мкг/мл Ү(III) готовили растворением точной навески оксида $\mathrm{Y}_{2} \mathrm{O}_{3}$ (99,9 \%) марки «ИтМ-І» (КГМК, Россия) в $1 \mathrm{M} \mathrm{HCl.}$

Раствор полигексаметиленгуанидин гидрохлорида Института эколого-технологических проблем (Москва) с концентрацией 7,5 \% готовили растворением точной навески реагента 
в деионизованной воде. Растворы оксина (8-оксихинолин-5-сульфокислоты натриевая соль) и феррона (7-йод-8-оксихинолин-5-сульфокислоты натриевая соль) фирмы Sigma-Aldrich с концентрацией 4,4 и 2,9 ммоль/л соответственно готовили растворением реагентов в деионизованной воде. Растворы реагентов с меньшей концентрацией готовили растворением исходных в деионизованной воде.

Силохром С-120 (размер частиц 0,1-0,2 мм, удельная поверхность $\sim 120 \mathrm{M}^{2} /$ г, средний диаметр пор $\sim 45$ нм) фирмы Люминофор (Ставрополь, Россия) использован в качестве матрицы для получения сорбентов.

В работе использовали $\mathrm{HCl}, \mathrm{HNO}_{3}$ «ос.ч.», дополнительно очищенные перегонкой на установке distillacid ${ }^{\mathrm{TM}}$ BSB-939-IR (Berghof). Растворы кислот с меньшими концентрациями готовили разбавлением исходных растворов деионизованной водой.

Деионизованную воду с удельным сопротивлением $18.3 \mathrm{M} \Omega \mathrm{cm}^{-1}$ получали на установке E-pure D4642-33 (Barnstead International).

\section{Оборудование}

Спектры возбуждения и люминесценции комплексов Y(III) с производными 8-оксихинолина в растворе и на поверхности регистрировали на спектрофлуориметре Cary Eclipse (Varian, Австралия) при условиях для $\mathrm{SiO}_{2}$-ПГМГ-феррон: спектральная ширина щели монохроматоров возбуждения и люминесценции 5 и 10 нм соответственно; диапазон длин волн: возбуждение $280-365$ нм $\left(\lambda_{\text {люм }}=485\right.$ нм), эмиссия $-400-600$ нм $\left(\lambda_{\text {возб }}=337\right.$ нм); эмиссионные фильтры - auto, фильтры возбуждения - auto; для $\mathrm{SiO}_{2}$-ПГМГ-оксин: спектральная ширина щели монохроматоров возбуждения и люминесценции 5 нм; диапазон длин волн: возбуждение - 300-400 нм $\left(\lambda_{\text {люм }}=481\right.$ нм), эмиссия $-400-600$ нм $\left(\lambda_{\text {возб }}=365\right.$ нм); эмиссионные фильтры $-360-1100$ нм, фильтры возбуждения - 250-395 нм.

Концентрацию Y(III) в растворах до и после сорбции определяли атомно-эмиссионным с индуктивно связанной плазмой методом на спектрометре iCAP 6500 (Thermo scientific, США) по градуировочным графикам. Построение градуировочных графиков и все расчеты проводились при помощи программного обеспечения прибора.

$\mathrm{pH}$ растворов до и после сорбции контролировали при помощи иономера Seven Multi (Mettler-Toledo, Швейцария).

\section{Послойное модифицирование кремнезема полигексамителенгуанидином}

и производными 8-оксихинолина

Поверхность кремнезема предварительно активировали раствором $\mathrm{NaOH}(\mathrm{pH}$ 9) при перемешивании в стеклянном стакане в течение 2 ч, промывали деионизированной водой до $\mathrm{pH}$ 6-7. Активированный кремнезем (10 г) модифицировали 0,1\%-ным раствором ПГМГ, добавляя 50 мл раствора при помощи перистальтического насоса со скоростью 2 мл/мин при постоянном перемешивании. Модифицированный кремнезем $\left(\mathrm{SiO}_{2}\right.$-ПГМГ) промывали деионизированной водой до отрицательной реакции промывных вод с бромфеноловым синим. Сорбент высушили при температуре $40{ }^{\circ} \mathrm{C}$ в сушильном шкафу и разделили на две равные порции. К 5 г полученного сорбента добавляли 100 мл раствора оксина или феррона с концентрацией $2,5 \cdot 10^{-5}-2,2 \cdot 10^{-3} \mathrm{M}$ и перемешивали в течение 30 мин. После раствор декантиро- 
вали, полученные сорбенты $\mathrm{SiO}_{2}$-ПГМГ-оксин $\left(\mathrm{SiO}_{2}\right.$-ПГМГ-феррон) промывали водой и сушили на воздухе в течение суток. Сорбенты не теряют своих сорбционных люминесцентных свойств в течение одного месяца.

Контроль за распределением оксина и феррона осуществляли по анализу водной фазы спектрофотометрическим методом по характеристической полосе реагента при 306 и 430 нм.

\section{Сорбиионное концентрирование}

и сорбиионно-люминесцентное определение Y(III)

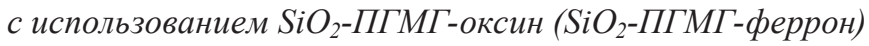

Сорбцию Y(III) изучали в статическом режиме. Для этого в градуированные пробирки с притертой пробкой вносили 1 мл раствора, содержащий 0,05-25 мкг/мл Y(III), добавляли $\mathrm{HNO}_{3}$ или $\mathrm{NaOH}$ для создания необходимого значения $\mathrm{pH}$, дистиллированную воду до объема 10 мл. Вносили 0,1 г сорбента $\mathrm{SiO}_{2}$-ПГМГ-Феррон, пробирки закрывали пробками и перемешивали в течение 1-30 мин.

Сорбент отделяли от раствора декантацией, помещали во фторопластовую кювету и измеряли коэффициент диффузного отражения. Контроль за распределением Y(III) осуществляли атомно-эмиссионным с индуктивно связанной плазмой методом.

\section{Отбор и пробоподготовка реальных образиов}

и сорбиионно-люминесиентное определение Y(III)

В качестве реальных объектов использовали образцы воды рек Красноярского края (р. Енисей, р. Кача). Речную воду (200 мл) отбирали с глубины 0,5 м, фильтровали через целлюлозную мембрану (Millipore, 0,45 мкм), подкисляли азотной кислотой до $\mathrm{pH} 1$ и кипятили в течение 30 мин. После охлаждения отбирали аликвоту (10 мл) переносили в стеклянную пробирку с притертой крышкой, доводили $\mathrm{pH}$ до 7,0 добавлением $\mathrm{NH}_{3} \cdot \mathrm{H}_{2} \mathrm{O}$, вносили 0,1 г сорбента $\left(\mathrm{SiO}_{2}\right.$-ПГМГ-феррон, $\mathrm{SiO}_{2}$-ПГМГ-оксин) и интенсивно перемешивали в течение 10 мин. Раствор декантировали. Сорбенты отделяли от раствора декантацией, помещали в кювету с кварцевым стеклом диаметром 1,0 см, высушивали фильтровальной бумагой и измеряли значение люминесценции. При определении Ү(ІІІ) с использованием $\mathrm{SiO}_{2}$-ПГМГ-феррон $\lambda_{\text {возб }}=337$ нм, $\lambda_{\text {люм }}=485$ нм; для $\mathrm{SiO}_{2}$-ПГМГ-оксин $\lambda_{\text {возб }}=365$ нм, $\lambda_{\text {люм }}=481$ нм.

Концентрацию Y(III) в природной воде определяли по градуировочному графику.

\section{Pacчетbl}

Степень извлечения $(R, \%)$ Y(III) сорбентами рассчитывали по формуле

$$
R=\frac{C_{0}-C}{C_{0}} \times 100 \%,
$$

где $C_{0}$ - исходная концентрация Y(III), ммоль/л; $C$ - концентрация Y(III) сорбции, ммоль/л.

Сорбционную емкость ( $q$, ммоль/г) сорбентов по отношению к Y(III) рассчитывали по уравнению

$$
q=\frac{\left(C_{0}-C\right) \times V}{m},
$$

где $V$ - объем раствора, л; $m$ - масса сорбента, г.

$$
-341-
$$


Предел обнаружения Y(III) с использованием сорбента $\mathrm{SiO}_{2}$-ПГМГ-Феррон рассчитывали по $3 s$-критерию.

\section{Результаты и обсуждение}

Условия сорбиионного концентрирования и сорбционно-люминесиентного

определения Y(III) с использованием кремнеземов,

модифииированных полигексаметиленгуанидином

и производными 8-оксихинолина

Сорбент $\mathrm{SiO}_{2}$-ПГМГ-оксин не окрашен, $\mathrm{SiO}_{2}$-ПГМГ-феррон имеет слабую желтую окраску $(\lambda=430$ нм), в процессе сорбции Y(III) на поверхности сорбентов образуется комплексное соединение, которое при облучении сорбента УФ-светом люминесцирует желто-зеленым светом при комнатной температуре, при $\lambda_{\text {люм }}=485$ нм (оксин) и $\lambda_{\text {люм }}=490$ нм (феррон). На рисунке 1 приведены спектры возбуждения люминесценции и люминесценции комплексов Y(III) на поверхности кремнеземов, модифицированных производными 8-оксихинолина.

Образующиеся люминесцирующие комплексы иттрия с производными 8-оксихинолина на поверхности сорбентов и в растворе имеют аналогичные спектральные характеристики (рис. 2), что говорит о сохранении свойств сульфопроизводных органического реагента на поверхности $\mathrm{SiO}_{2}-П Г М Г$.

Для поверхностных комплексов иттрия(III) с оксином и ферроном наблюдается гипсохромный сдвиг спектров люминесценции на $~ 20$ нм по сравнению со спектрами люминесценции его комплексов в растворе (рис. 2). Сдвиг в коротковолновую область обусловлен взаимодействием комплексов иттрия(III) с оксином и ферроном с более полярными, чем вода, гуанидиновыми группами ПГМГ, закрепленными на поверхности кремнезема.

В дальнейшем определение Y(III) на поверхности сорбентов проводили при $\lambda_{\text {возб }}=365$ нм, $\lambda_{\text {люм }}=485$ нм $\left(\mathrm{SiO}_{2}\right.$-ПГМГ-оксин) и при $\lambda_{\text {возб }}=338$ нм, $\lambda_{\text {люм }}=490$ нм $\left(\mathrm{SiO}_{2}\right.$-ПГМГ-феррон $)$.

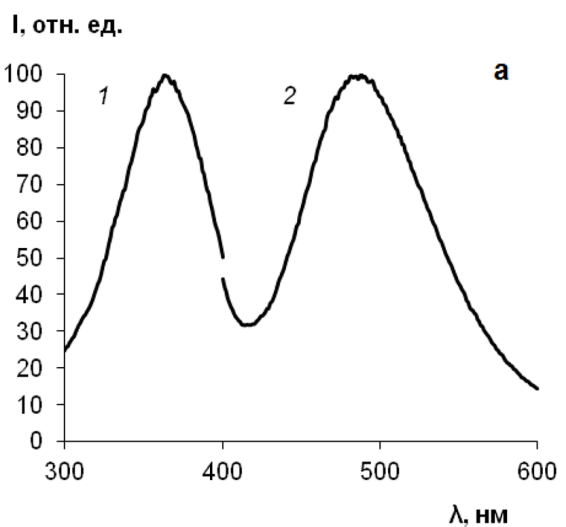

\section{І, отн. ед.}

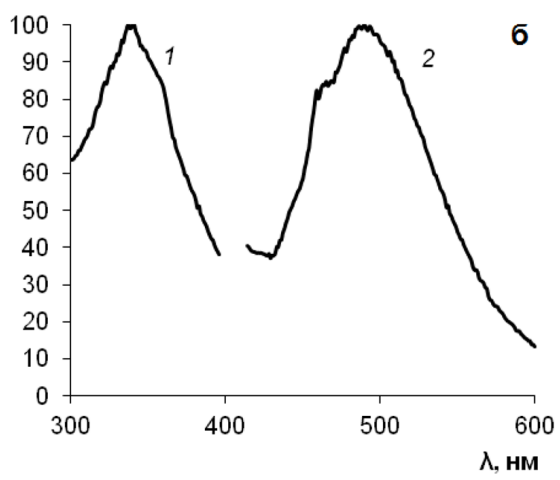

Рис. 1. Нормированные спектры возбуждения люминесценции (1) и люминесценции (2) комплекса Y(III) с оксином (а) и ферроном (б) на поверхности $\mathrm{SiO}_{2}-$ ПГМГ $\left(\mathrm{C}_{\mathrm{Y}(\mathrm{III})}=0,25\right.$ мкг/мл; $\mathrm{V}=10$ мл; $\mathrm{pH} 6,5 ; \mathrm{t}=15$ мин $)$

Fig. 1. Normalized excitation (1) and luminescence (2) spectra of the Y(III) complexes with oxine (a) and ferron (b) on the $\mathrm{SiO}_{2}$-PHMG surface $\left(\mathrm{C}_{\mathrm{Y}(\mathrm{III})}=0,25 \mu \mathrm{g} / \mathrm{mL} ; \mathrm{V}=10 \mathrm{~mL} ; \mathrm{pH} 6,5 ; \mathrm{t}=15 \mathrm{~min}\right)$ 


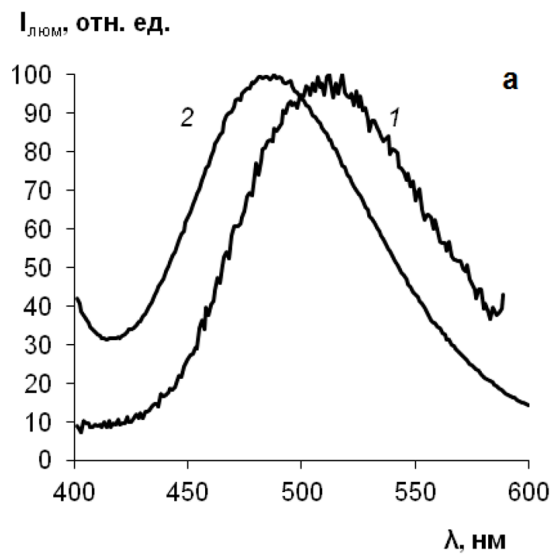

$\mathbf{I}_{\text {люм }}$ отн. ед.

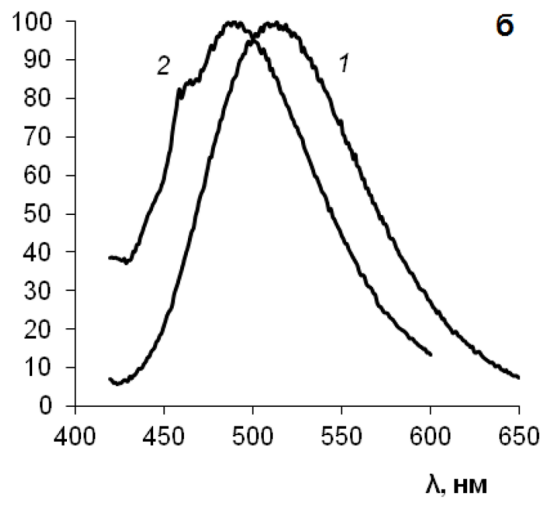

Рис. 2. Нормированные спектры люминесценции комплекса Y(III) с оксином (а) и ферроном (б) в растворе (1) и на поверхности $\mathrm{SiO}_{2}$-ПГМГ (2) $\left(\mathrm{C}_{\mathrm{Y}(\mathrm{III})}=0,25\right.$ мкг/мл; $\mathrm{V}=10$ мл; $\mathrm{pH} 6,0 ; \mathrm{t}=15$ мин)

Fig. 2. Normalized luminescence spectra of Y(III) complex with oxine (a) and ferron (b) in solution (1) and on the surface of $\mathrm{SiO}_{2}$-PHMG (2) $\left(\mathrm{C}_{\mathrm{Y}(\mathrm{III})}=0,25 \mu \mathrm{g} / \mathrm{mL} ; \mathrm{V}=10 \mathrm{~mL} ; \mathrm{pH} 6,0 ; \mathrm{t}=15 \mathrm{~min}\right)$

Влияние времени контакта фаз и кислотности среды

на степень извлечения Y(III) и образование люминесиирующих комплексов

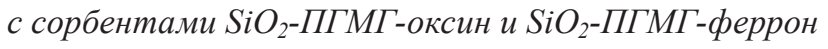

Время установления сорбционного равновесия для $\mathrm{SiO}_{2}$-ПГМГ-оксин ( $\mathrm{SiO}_{2}$-ПГМГ-феррон) по отношению к Y(III) ( $>$ > 95 \%) и развития максимальной интенсивности излучения поверхностных комплексов не превышает 10 мин (рис. 3).

Время установления сорбционного равновесия и развития максимальной интенсивности люминесценции комплексов Y(III) на поверхности не зависит от типа исследуемого сорбента.
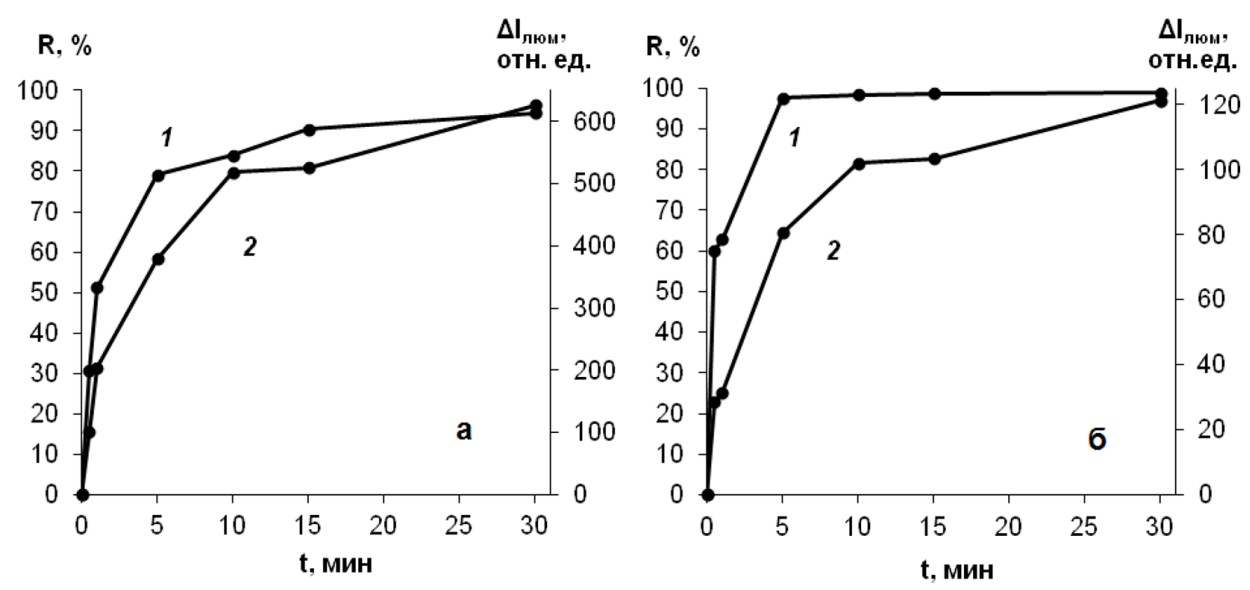

Рис. 3. Зависимость степени извлечения Y(III) (1) сорбентами $\mathrm{SiO}_{2}$-ПГМГ-оксин (а) и $\mathrm{SiO}_{2}$-ПГМГ-феррон (б) и интенсивности люминесценции поверхностных комплексов (2) от времени контакта фаз $\left(\mathrm{C}_{\mathrm{Y}(\mathrm{III})}=0,25\right.$ мкг/мл; $\mathrm{V}=10$ мл; $\mathrm{m}_{\text {сорб }}=0,1$ г; $\mathrm{pH} 7,5$ (a), $\mathrm{pH}$ 6,0 (б))

Fig. 3. Dependence of the extraction of $\mathrm{Y}(\mathrm{III})$ (1) by $\mathrm{SiO}_{2}-\mathrm{PHMG}-$ oxine (a) and $\mathrm{SiO}_{2}-\mathrm{PHMG}$-ferron (b) adsorbents and the intensity of luminescence of surface complexes (2) vs. phase contact time $\left(\mathrm{C}_{\mathrm{Y}(\mathrm{III})}=0,25 \mu \mathrm{g} / \mathrm{mL} ; \mathrm{V}=10 \mathrm{~mL}\right.$; $\mathrm{m}_{\text {adsorbent }}=0,1 \mathrm{~g} ; \mathrm{pH} 7,5$ (a), $\mathrm{pH}$ 6,0 (b)) 

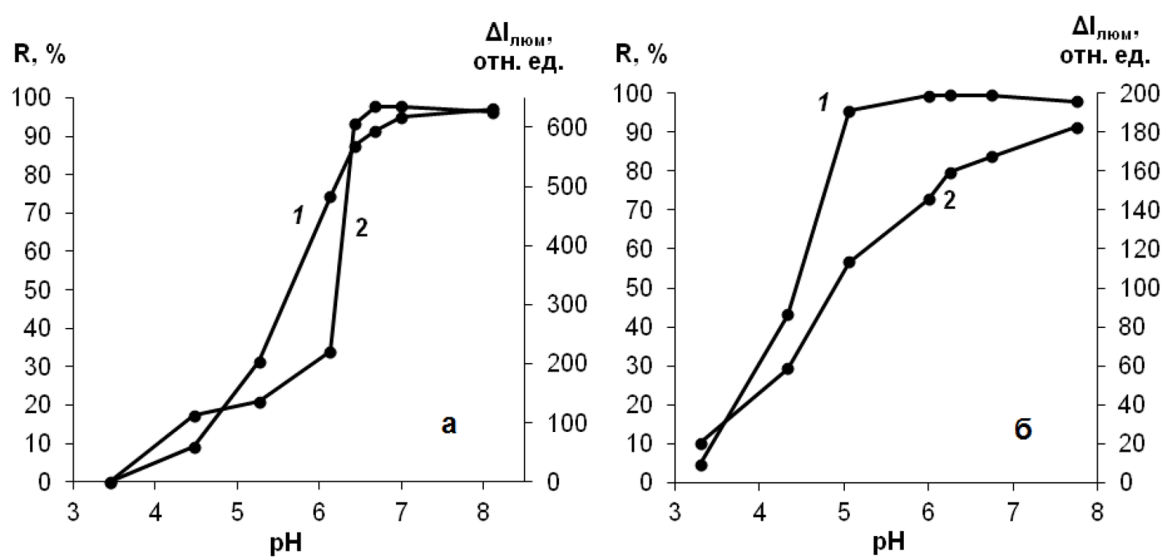

Рис. 4. Зависимость степени извлечения Ү(III) (1) сорбентами $\mathrm{SiO}_{2}$-ПГМГ-оксин (а) и $\mathrm{SiO}_{2}$-ПГМГ-феррон (б) и интенсивности люминесценции поверхностных комплексов (2) от кислотности среды (С)(III) $=0,25$ мкг/ мл; $\mathrm{V}=10$ мл; $\mathrm{m}_{\text {сорб }}=0,1$ г; $\mathrm{t}=15$ мин)

Fig. 4. Dependence of the extraction of Y(III) (1) by $\mathrm{SiO}_{2}-\mathrm{PHMG}$-oxine (a) and $\mathrm{SiO}_{2}-\mathrm{PHMG}$-ferron (b) adsorbents and the intensity of luminescence of the surface complexes (2) vs. the acidity of medium $\left(\mathrm{C}_{\mathrm{Y}(\mathrm{III})}=0,25 \mu \mathrm{g} / \mathrm{mL}\right.$; $\left.\mathrm{V}=10 \mathrm{~mL} ; \mathrm{m}_{\text {adsorbent }}=0,1 \mathrm{~g} ; \mathrm{t}=15 \mathrm{~min}\right)$

Диапазон рН количественного извлечения $\mathrm{Y}(\mathrm{III}) \mathrm{SiO}_{2}$-ПГМГ-оксин (> 98 \%) совпадает с диапазоном максимальной интенсивности люминесценции и составляет $\mathrm{pH}$ 6,0-8,0 (рис. 4a). Диапазон рН количественного извлечения $\mathrm{Y}(\mathrm{III}) \mathrm{SiO}_{2}$-ПГМГ-феррон (> 98 \%) совпадает с диапазоном максимальной интенсивности люминесценции - $\mathrm{pH}$ 5,0-7,0 (рис. 46).

Сорбент $\mathrm{SiO}_{2}$-ПГМГ-феррон извлекает Y(III) и образует с ним люминесцирующие комплексы при более низких значениях $\mathrm{pH}$, чем сорбент $\mathrm{SiO}_{2}$-ПГМГ-оксин. В молекуле феррона в отличие от оксина присутствует заместитель I, характеризующийся выраженным отрицательным индуктивным эффектом $(-I)$, способствующим делокализации электронной плотности и усилению кислотных свойств в молекуле, как следствие, феррон не только закрепляется на поверхности $\mathrm{SiO}_{2}$-ПГМГ [17], но также извлекает Y(III) при более низких значениях $\mathrm{pH}$.

Изотермы сорбичи Y(III) с использованием сорбентов $\mathrm{SiO}_{2}$-ПГМГ-феррон

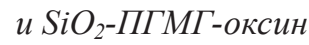

Изотермы сорбции Y(III) кремнеземами, модифицированными производными 8-оксихинолина, относятся к L-типу (рис. 5).

Из горизонтальных участков изотерм сорбции определена сорбционная емкость по Y(III), которая составляет 0,81 мкмоль/Г ( $\mathrm{SiO}_{2}$-ПГМГ-феррон) и 0,97 мкмоль/Г ( $\mathrm{SiO}_{2}$-ПГМГ-оксин). Сопоставление количества реагента, закрепленного на поверхности (2,8 мкмоль/г), с сорбционной емкостью $\mathrm{SiO}_{2}$-ПГМГ-феррон и $\mathrm{SiO}_{2}$-ПГМГ-оксин по Y(III) позволяет предположить состав комплекса на поверхности $\mathrm{Me}: \mathrm{R}=1: 3$, комплексы аналогичного состава образуются в растворах [18], что подтверждает сохранение свойств производных 8-оксихинолина на поверхности $\mathrm{SiO}_{2}-П Г М Г$. 


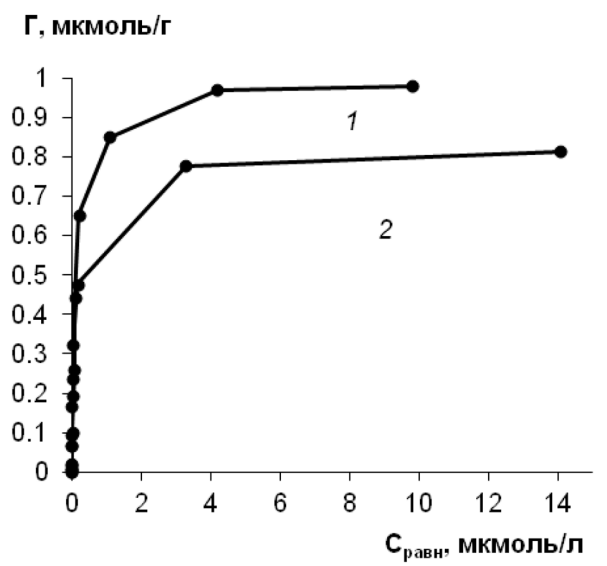

Рис. 5. Изотермы сорбции Ү(III) на поверхности сорбентов с функциональными группами оксина (1) и феррона (2) $\left(\mathrm{V}=10\right.$ мл; $\mathrm{m}_{\text {сорб }}=0,1$ г; $\mathrm{pH} 7,0 ; \mathrm{t}=15$ мин $)$

Fig. 5. Adsorption isotherms of Y(III) on the surface of adsorbents with functional groups of oxine (1) and ferron (2) $\left(\mathrm{V}=10 \mathrm{~mL} ; \mathrm{m}_{\text {adsorbent }}=0,1 \mathrm{~g} ; \mathrm{pH} 7,0 ; \mathrm{t}=15 \mathrm{~min}\right)$

\section{Сорбционно-люминесцентное определение Y(III)}

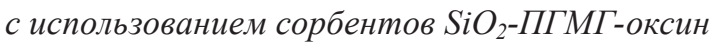

и $\mathrm{SiO}_{2}$-ПГМГ-феррон в природных водах

Образование люминесцирующих комплексов $\mathrm{Y}(\mathrm{III})$ на поверхности сорбентов $\mathrm{SiO}_{2}$ ПГМГ-феррон и $\mathrm{SiO}_{2}$-ПГМГ-оксин и увеличение интенсивности их люминесценции при 490 и 485 нм соответственно положены в основу разработки сорбционно-люминесцентной методики определения Y(III). Зависимость интенсивности люминесценции поверхностных комплексов от концентрации Ү(ІІІ) в растворе приведена на рис. 6.

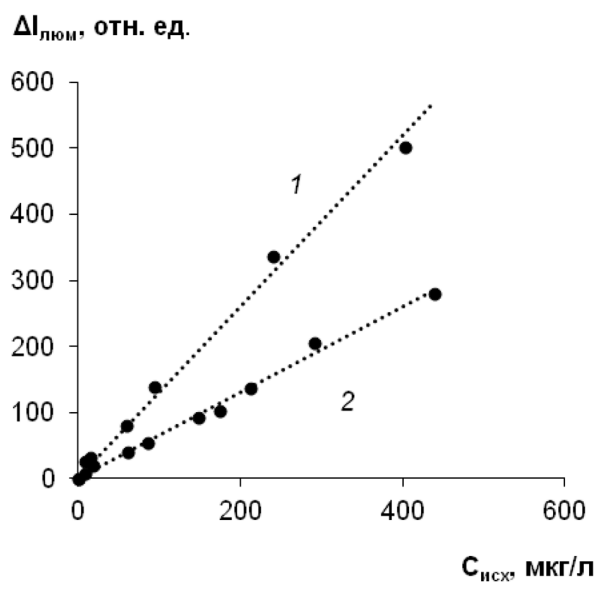

Рис. 6. Зависимость интенсивности люминесценции поверхностного комплекса Y(III) с функциональными группами оксина (1) и феррона (2) от концентрации $\mathrm{Y}(\mathrm{III})$ в растворе ( $\mathrm{V}=10$ мл; pH 6,5; $\mathrm{m}_{\text {сорб }}=0,1$ г; $\mathrm{t}=15$ мин)

Fig. 6. Dependence of the luminescence intensity of the Y(III) surface complex with the functional groups of oxine (l) and ferron (2) vs. the concentration of $\mathrm{Y}(\mathrm{III})$ in solution $\left(\mathrm{V}=10 \mathrm{~mL} ; \mathrm{pH} 6,5 ; \mathrm{m}_{\text {adsorbent }}=0,1 \mathrm{~g}\right.$; $\mathrm{t}=15 \mathrm{~min})$ 
Таблица 1. Метрологические характеристики сорбционно-люминесцентного определения Y(III)

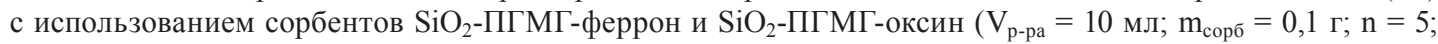
$\mathrm{p}=0,95 ; \mathrm{pH} 6,5)$

Table 1. Analytical performance of the adsorption-luminescent determination of Y(III) using $\mathrm{SiO}_{2}$-PHMG-ferron and $\mathrm{SiO}_{2}$-PHMG-oxin adsorbents $\left(\mathrm{V}=10 \mathrm{~mL} ; \mathrm{m}_{\text {adsorbent }}=0,1 \mathrm{~g} ; \mathrm{n}=5 ; \mathrm{p}=0,95 ; \mathrm{pH} 6,5\right)$

\begin{tabular}{|c|c|c|c|c|c|c|}
\hline \multicolumn{1}{|c|}{ Сорбент } & $\begin{array}{c}\text { Концентрация } \\
\text { реагента, мкмоль } / \Gamma\end{array}$ & $\begin{array}{c}\text { ДОС*, } \\
\text { мкг/л }\end{array}$ & $\begin{array}{r}\text { Предел } \\
\text { обнаружения, мкг/л }\end{array}$ & Уравнение & $\mathrm{R}^{2}$ & $\mathrm{~S}_{\mathrm{r}}$ \\
\hline $\mathrm{SiO}_{2}$-ПГМГ-феррон & 2,8 & $6-500$ & 2,0 & $\Delta \mathrm{I}_{\text {люм }}=0,65 \cdot \mathrm{C}_{\mathrm{Y}}$ & 0,993 & 0,03 \\
\hline $\mathrm{SiO}_{2}$-ПГМГ-оксин & 2,8 & $4-400$ & 1,0 & $\Delta \mathrm{I}_{\text {люм }}=1,30 \cdot \mathrm{C}_{\mathrm{Y}}$ & 0,992 & 0,01 \\
\hline
\end{tabular}

*ДОС - диапазон определяемых содержаний.

Метрологические характеристики сорбционно-люминесцентного определения Ү(III) представлены в табл. 1 .

Поверхность сорбента $\mathrm{SiO}_{2}$-ПГМГ-феррон окрашена в желтый цвет, который уменьшает интенсивность люминесценции поверхностных комплексов Y(III) с ферроном, что приводит к снижению его предела обнаружения по сравнению с комплексами с оксином.

Для определения селективности определения создавались бинарные системы, содержащие иттрий на фоне возрастающей концентрации сопутствующего элемента. Сорбционно-люминесцентному определению Y(III) с концентрацией 0,2 мг/л (0,1 г $\mathrm{SiO}_{2}$ ПГМГ-феррон, pH 6,5) не мешают в кратных количествах: $\mathrm{Na}(\mathrm{I}), \mathrm{K}(\mathrm{I}), \mathrm{Ca}(\mathrm{II})(1000), \mathrm{Mg}(\mathrm{II})$ (500); Fe(III) (20); La(III), Sm(III), Gd(III), Eu(III) (10); Al(III), Cu(II), Mn(II) (1). Мешающее влияние $\mathrm{Cu}(\mathrm{II})$ устраняли введением $0,2 \%$-го раствора тиомочевины. Окрашенные в зеленый цвет поверхностные комплексы феррона с Fe(III) образуются при pH 2-3 [19], поэтому железо(III) в меньшей степени мешает определению Y(III). Сорбционно-люминесцентному определению Y(III) с $\mathrm{SiO}_{2}$-ПГМГ-феррон не мешает солевой фон до 2 г/л по $\mathrm{Na}_{2} \mathrm{SO}_{4}, \mathrm{NaNO}_{3}$, $\mathrm{NaCl}, \mathrm{Na}_{2} \mathrm{CO}_{3}$.

Определению 2 мкг Y(III) на поверхности 0,1 г $\mathrm{SiO}_{2}$-ПГМГ-оксин при $\mathrm{pH}$ 6,5 не мешают в кратных количествах: $\mathrm{Na}(\mathrm{I}), \mathrm{K}(\mathrm{I}), \mathrm{Ca}(\mathrm{II})$ (1000), $\mathrm{Mg}$ (II) (200), $\mathrm{Fe}(\mathrm{III})$ (10); La(III), Sm(III), $\mathrm{Gd}(\mathrm{III}), \mathrm{Eu}(\mathrm{III})(5)$; $\mathrm{Al}(\mathrm{III}), \mathrm{Cu}(\mathrm{II}), \mathrm{Mn}(\mathrm{II})$ (1). Мешающее влияние $\mathrm{Cu}(\mathrm{II})$ устраняли введением 0,2\%-го раствора тиомочевины. Сорбционно-люминесцентному определению Y(III) не мешает солевой фон до 1 г/л $\mathrm{Na}_{2} \mathrm{SO}_{4}, \mathrm{NaNO}_{3}, \mathrm{NaCl}, \mathrm{Na}_{2} \mathrm{CO}_{3}$.

Методика сорбционно-люминесцентного определения $\mathrm{Y}(\mathrm{III})$ с использованием $\mathrm{SiO}_{2}$ ПГМГ-феррон опробована при анализе природных вод Красноярского края (табл. 2). Несмотря на то что предел обнаружения Ү(ІІІ) ниже для сорбционно-люминесцентной методики определения с использованием $\mathrm{SiO}_{2}$-ПГМГ-оксин, кремнезем с функциональными группами феррона позволяет извлекать и определять Ү(ІІІ) при более низких значениях $\mathrm{pH}$, а также характеризуется меньшим мешающим влиянием сопутствующих ионов.

Правильность разработанной методики подтверждена методом добавок. 
Таблица 2. Результаты сорбционно-люминесцентного определения Y(III) в природной воде

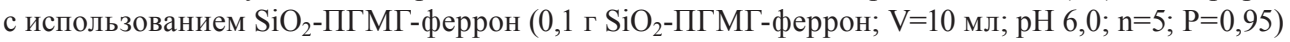

Table 2. Results of adsorption-luminescent determination of $\mathrm{Y}(\mathrm{III})$ in natural water using $\mathrm{SiO}_{2}$-PHMG-ferron $\left(0,1 \mathrm{~g}\right.$ of $\mathrm{SiO}_{2}-\mathrm{PHMG}-$ ferron; $\left.\mathrm{V}=10 \mathrm{~mL} ; \mathrm{pH} 6,0 ; \mathrm{n}=5 ; \mathrm{P}=0,95\right)$

\begin{tabular}{|c|c|c|}
\hline Образец & Введено, мг/л & Найдено, мг/л \\
\hline \multirow{3}{*}{ р. Енисей } & - & $<П р О$ \\
\cline { 2 - 3 } & 0,030 & $0,032 \pm 0,004$ \\
\cline { 2 - 3 } & 0,060 & $0,063 \pm 0,005$ \\
\hline \multirow{3}{*}{ р. Б. Кача } & - & $<П р О$ \\
\cline { 2 - 3 } & 0,040 & $0,044 \pm 0,005$ \\
\cline { 2 - 3 } & 0,080 & $0,086 \pm 0,005$ \\
\hline
\end{tabular}

\section{Заключение}

В данной работе исследованы и определены условия образования поверхностных люминесцирующих комплексов Y(III) с сульфопроизводными 8-гидроксихинолина. В процессе сорбции Y(III) на поверхности сорбентов образуется комплексное соединение, которое при облучении сорбента УФ-светом люминесцирует желто-зеленым светом при комнатной температуре при $\lambda_{\text {люм }}=485$ нм (оксин) и $\lambda_{\text {люм }}=490$ нм (феррон). Диапазон рН количественного извлечения Y(III) предложенными сорбентами совпадает с диапазоном максимальной интенсивности люминесценции и составляет рН 6,0-8,0 ( $\mathrm{SiO}_{2}$-ПГМГ-оксин) и рН 5,0-7,0 ( $\mathrm{SiO}_{2}$-ПГМГ-феррон). На основе полученных данных разработаны методики сорбционно-люминесцентного определения Y(III), предел обнаружения Ү(ІІІ) составляет 1 мкг/л $\left(\mathrm{SiO}_{2}\right.$-ПГМГ-оксин) и 2 мкг/л $\left(\mathrm{SiO}_{2}\right.$ ПГМГ-феррон). Разработанные методики опробованы при определении иттрия в реках Енисей и Кача Красноярского края. Правильность разработанных методик подтверждена методом добавок.

\section{Благодарности / Acknowledgments}

Исследование выполнено при финансовой поддержке РФФИ, Правительства Красноярского края и Красноярского краевого фонда науки в рамках научного проекта № 20-43-242905.

The research was funded by RFBR, Krasnoyarsk Territory and Krasnoyarsk Regional Fund of Science, project number № 20-43-242905.

\section{Список литературы / References}

1. Pagano G., Aliberti F., Guida M., Oral R., Siciliano A., Trifuoggi M., Tommasi F. Rare earth elements in human and animal health: state of art and research priorities. Environmental research 2015. Vol. 142, P. 215-220. doi: 10.1016/j.envres.2015.06.039

2. Buckingham S., Maheswaran J., Meehan. B, Peverill K. The role of applications of rare earth elements in enhancement of crop and pasture production. Materials science forum 1999. Vol. 315, P. 339-347. doi: 10.4028/www.scientific.net/MSF.315-317.339

3. Li Y., Yang J. L., Jiang Y. Tracer are earth element detection in food and agricultural products based on flow injection walnut shell packed microcolumn preconcentration coupled with inductively

$$
-347-
$$


coupled plasma mass spectrometry. Journal of agricultural and food chemistry 2012. Vol. 60, P. 30333041. doi: $10.1021 /$ jf2049646

4. Xu X., Zhu W., Wang Z., Witkamp G. Distributions of rare earths and heavy metals in fieldgrown maize after application of rare earth-containing fertilizer. Science of the total environment 2002. Vol. 293, P. 97-105. doi: 10.1016/S0048-9697(01)01150-0

5. Ramos S. J., Dinali G., Oliveira C., Martins G. C., Moreira C. G., Siqueira J. O., Guilherme L. R.G. Rare earth elements in the soil environment. Current pollution reports 2016. Vol. 2, P. 28-50. doi: 10.1007/s40726-016-0026-4

6. Benedetto A., Bocca C., Brizio P., Cannito S., Abete M.C., Squadrone S. Effects of the rare element's lanthanum and cerium on the growth of colorectal and hepatic cancer cell lines. Toxicology in Vitro 2018. Vol. 46, P. 9-18. doi: 10.1016/j.tiv.2017.09.024

7. Herrmann H., Nolde J., Berger S., Heise S. Aquatic ecotoxicity of lanthanum - a review and an attempt to derive water and sediment quality criteria. Ecotoxicology and environmental safety 2016. Vol. 124, P. 213-238. doi: 10.1016/j.ecoenv.2015.09.033

8. Aniwashi J., Kaleri H.A., Sulaiman Y., Qifa L., Zhuang X. Interactions between rare-earth ions and DNA of Bashibai sheep. Genetics and molecular research 2011. Vol. 10, P. 1075-1083. doi: 10.4238/vol10-2gmr1070

9. Zhu W., Xu S., Shao P., Zhang H., Wu D., Yang W., Feng J. Bioelectrical activity of the central nervous system among populations in a rare earth element area. Biological trace element research 1997. Vol. 57, P. 71-77. doi: 10.1007/BF02803871

10. Pagano G., Thomas P. J., Di Nunzio A., Trifuoggi M. Human exposures to rare earth elements: present knowledge and research prospects. Environmental Research 2019. Vol. 171, P. 493-500. doi: 10.1016/j.envres.2019.02.004

11. [Электронный ресурс] Priorities for Occupational Safety and Health Research in Europe: 2013 2020, European Agency for Safety and Health at Work (EU body or agency) (2015). https://osha.europa. eu/en/publications/reports/priorities-for-occupational-safety-and-health-research-in-europe-2013-2020

12. Hanana H., Turcotte P., Dubé M., Gagnon C. and Gagné F. Response of the freshwater mussel, Dreissena polymorpha to sub-lethal concentrations of samarium and yttrium after chronic exposure. Ecotoxicology and environmental safety 2018. Vol. 165, P. 662-670. doi: 10.1016/j.ecoenv.2018.09.047

13. Rao, T. and Biju, V. Trace Determination of Lanthanides in Metallurgical, Environmental, and Geological Samples. Critical reviews in analytical chemistry 2000. Vol. 30, P. 179-220. doi: $10.1080 / 10408340091164234$

14. Salinas F., Muñoz de la Peña A., Murillo J.A. Spectrofluorimetric Determination of Y(III) with 1-Hydroxy-2-Carboxyanthraquinone. Analytical letters 1984. Vol. 17, P. 497-505. doi: 10.1080/00032718408065297

15. Rao T.P., Vijayalakshmi B., Iyer C.S.P. Fluorimetric/luminescence determination of lanthanides. Reviews in Analytical Chemistry 2001. Vol. 20, P. 27-61. doi: 10.1515/REVAC.2001.20.1.27

16. Meshkova S., Doga, P. Increasing Sensitivity of the Luminescence Determination of Lanthanides Using Their Complexes. Journal of analytical chemistry 2020. Vol. 75, P. 286-303. doi: 10.1134/S1061934820030144

17. Didukh-Shadrina S., Buyko O. and Losev V. Solid-phase extraction and fluorimetric determination of $\mathrm{Zn}(\mathrm{II})$ in natural water using novel adsorbent based on silica modified with 
polyhexamethylene guanidine and Ferron. International journal of environmental analytical chemistry 2019, P. 1-13. doi: 10.1080/03067319.2019.1674846

18. Manku G.S. The formation constants of lanthanon(III) complexes with 7-iodo-8hydroxyquinoline-5-sulphonic acid. Journal of the less-common metals 1971. Vol. 24, P. 475-476.

19. Didukh-Shadrina S., Buyko O. and Losev V. Adsorption-Photometric and Test-Determination of Fe (III) in Natural Water Using Silica Lyer-by-Lyer Modified with Polyhexamethylene Guanidine and Ferron. Journal of Siberian Federal University. Chemistry 2020. Vol. 13, P. 349-362. 